\title{
Pre-transfusion serological testing: are we doing it right?
}

\section{Mini Review}

Pre-transfusion testing is performed to ensure the normal survival of transfused red blood cell products i.e. to prevent hemolytic transfusion reaction via immune-mediated mechanism. ${ }^{1}$ The serological part of pre-transfusion testing includes; $\mathrm{ABO}$ group and Rh (D) type, antibody screening and crossmatching. ${ }^{2}$ Antibody screening is included to detect unexpected antibody and was first introduced after the discovery of Coombs test "antiglobulin test" in 1945. With the characterization of more red blood cell antibodies, more tests and different techniques were introduced. The main goal of antibody screening test is to maximize the detection of so called clinically significant antibodies and in the same content to minimize the detection of clinically insignificant antibodies. ${ }^{4}$ In order to meet this general aim many tests and techniques were initiated the first of which was the indirect antiglobulin test (IAT). ${ }^{3}$ Antiglobulin sera (AHG) may have different specificities; monospecific AHG sera such as anti-IgG and anti-C $3 \mathrm{~d}$ or polyspecific that contain both anti-IgG and anti-C $3 \mathrm{~d}^{5,6}$ Furthermore, in order to decrease the testing time and/or to increase the sensitivity of the testing outcome, many enhancement media have been described to be used in conjunction with the IAT. An example of the additives is albumin that helps reduce repulsive forces between red blood cells. ${ }^{7}$ Another example is that of low ionic strength solution (LISS) which reduces the ionic strength accelerating antibody binding to red cells. ${ }^{8}$ In addition includes polyethylene glycol (PEG), which is a water-soluble linear polymer that potentiates antigen-antibody reactions. ${ }^{9}$

Being the first and the most widely used method for antibody detection, IAT has attracted the interest of the researchers and the biomedical companies to incorporate this method in the platform of new technology. After being used as conventional IAT tube test, ${ }^{3}$ Rosenfield et al..$^{10}$ described a solid-phase method as an alternative to tube method in $1978^{10,11}$ that have comparable results as that of the tube methods and higher sensitivity, which then become a base for many blood bank automated systems. In 1990, Lapierre et al. ${ }^{12}$ defined a new method, which utilized microtubes filled with a mixture of gel, that can provide clear and stable reactions leading to improvement in the interpretation of results. ${ }^{12}$ The so called column agglutination system has largely replaced the conventional tube methods and incorporated in most of the blood bank automated systems. ${ }^{13}$

In addition to the IAT, there are other serological tests described for antibody detection purposes. One of these methods is the enzyme test, which is not routinely used for antibody detection but rather utilized as an effective tool in antibody identification processes., ${ }^{4,14}$ Another method described by Lalezari et al..$^{15}$ in 1967, which was found to be useful and very sensitive, is Polybrene method..$^{15}$ Owing to its simplicity and sensitivity, polybrene test is not only available as manual rapid test but also in the automated system. ${ }^{16}$ As with every serological test, pre-transfusion serological testing has limitations with respect to their sensitivity. Based upon the fact that IAT becomes the principle test for antibody screening and crossmatching since its
Volume I Issue 2 - 2015

\author{
Yousef H Altaha,' Denise E Jackson² \\ 'Maternity and Children Hospital, Ministry of Health, Saudi \\ Arabia \\ ${ }^{2}$ School of Medical Sciences, RMIT University, Australia
}

Correspondence: Yousef H Altaha, Laboratory \&Blood Bank Department, Maternity and Children Hospital, Imam Ali Ibnabi Taleb Street, Dammam 32253, Eastern Provence, Saudi Arabia, Tel +966559887744, Email Yousef.altaha@gmail.com

Received: July 02, 2015 | Published: July 17, 2015

introduction in 1945, many failures within its capacity to detect clinical significant antibody have been reported. ${ }^{17,18}$ Some of these failures are due to inadequate anti-complement activity of AHG reagent as reported by Sherwood et al. ${ }^{17}$ where haemolytic transfusion reaction resulted from failure of antiglobulin reagents to detect complement. ${ }^{17}$ Other failures are linked to the sensitivity of IAT itself.

Snyder et al. ${ }^{18}$ reported intravascular haemolytic transfusion reaction caused by anti-e that was not detected by routine IAT and enzyme tests but can be demonstrated solely by an Auto AnalyzerPolybrene (AAP) system. ${ }^{18}$ Moreover another intravascular haemolytic transfusion reaction was reported by Maynard et al. ${ }^{19}$ caused initially by anti-Jk ${ }^{\mathrm{a}}$, but anti-C and anti-E were demonstrated too, that again were undetectable by low-ionic-strength antiglobulin (LISS-IAT) methods and could only be demonstrated by manual polybrene test. ${ }^{19}$ A recent report by Powers et al. confirmed the failure of LISS-IAT test in detecting very weakly reactive antibody which might lead to haemolytic transfusion reaction. ${ }^{20}$ Despite its evident sensitivity, Liu et al. reported low and limited sensitivity of polypbrene test in detecting antibodies to Kidd blood group system. ${ }^{21}$

The availability of a vast number of techniques and methods for antibody detection makes the exploration of an ideal method for antibody screen necessary. In one study, the sensitivity of manual low-ionic hexadimethrine bromide (Polybrene, LIP) and low- ionic Polybrene indirect antiglobulin tests (LIPAT) were compared with those of a manual low-ionic-strength indirect antiglobulin test (LISSIAT) by using a commercial Polybrene kit. This study found that the ability of polybrene in antibody detection is superior to that of manual LISS-IAT methods except for anti-K and the failure with anti-K making it not suitable as primary test for antibody screening on its own. ${ }^{22}$ However, the sensitivity for the Kell system is significantly improved by performing a complementary antiglobulin test on the sensitized, Polybrene-treated, red blood cells. ${ }^{23}$ In another blinded study that compared PEG and LISS demonstrates a relatively high false-positive rate with PEG methods despite its higher sensitivity than LISS in detecting clinically significant antibodies. ${ }^{24}$ In a similar study that looked at the polyethylene glycol antiglobulin test and the use of enzymes in antibody detection and identification showed an 
analogous results between the two methods with lower exposure to false positive and the detection of clinically non-relevant antibody in PEG methods. ${ }^{25}$

With the popularity of microtube antiglobulin column agglutination system, Weisbach et al. ${ }^{26}$ showed that the sensitivity of a number of microtube column systems in the detection of clinically significant antibodies was similar and was markedly superior to that of the tube LISS-IAT. $^{26,27}$ In contrast, Pinkerton et al. ${ }^{28}$ reported that the gel LISS-IAT had the same sensitivity as a well-performed tube LISSIAT method. ${ }^{28}$ Moreover, Phillips et al. ${ }^{29}$ showed the gel LISS-IAT had a lower sensitivity than tube LISS-IAT using four examples of difficult and weak-reacting red blood cell antibodies. ${ }^{29}$ Furthermore, the gel column method was found to be similar to the tube PEG-IAT in detecting clinically significant antibodies but detects fewer clinically insignificant antibodies. ${ }^{30}$

Based upon the available studies there is not a single ideal method for antibody screening in pre-transfusion testing. What was found to be more sensitive in one study, such as the LISS-IAT gel column system, was found to be equally or even less sensitive by other studies. The status of high sensitivity in detecting the presence of red cell antibodies irrespective of their clinical relevance has to re-evaluated because some of the clinically insignificant antibody were reported to be a primary cause of delayed haemolytic transfusion reaction and vice versa. ${ }^{31}$ Moreover, the status of only one test for antibody screening need to be looked at and the possibility of incorporating primary and secondary test might be examined. Therefore, the question of whether we are doing the pre-transfusion serological test RIGHT is still opened for investigation and re-evaluation.

\section{Acknowledgements}

None.

\section{Conflict of interest}

The author declares no conflict of interest.

\section{References}

1. Price TH. Standards for blood banks and transfusion services. 26th ed. Bethesda, USA: AABB; 2009. p. 33-34.

2. Katharine AD, Ira AS. Pre transfusion testing, Technical manual. 16th ed. Bethesda, USA: AABB; 2008. p. 437-460.

3. Coombs RR, Mourant AE, Race RR. A new test for the detection of weak and "incomplete" Rh agglutinins. Br J Exp Pathol. 1945;26(4):255-266.

4. Phyllis SW. Identification of antibodies to red cell antigens, Technical manual. 16th ed. Bethesda, USA: AABB; 2008. p. 465-497.

5. Polley MJ, Mollison PL. The role of complement in the detection of blood group antibodies: special reference to the antiglobulin test. Transfusion. 1961;1(1):9-22.

6. Wright MS, Issitt PD. Anticomplement and the indirect antiglobulin test Transfusion. 1979;19(6):688-694.

7. Clayton EM, Brown RB, Bove JR. The antiglobulin reaction on albumin enriched cell suspensions. Transfusio. 1965;5(4):344-349.

8. Moore HC, Mollison PL. Use of a Low-ionic-strength medium in manual tests for antibody detection. Transfusion. 1976;16(4):291-296.

9. Nance SJ, Garratty G. Polyethylene glycol: A new potentiator of red blood cell antigen-antibody reaction. Am J ClinPathol. 1987;87(5):633635 .
10. Rosenfield RE, Kochwa S, Kaczcra Z. Solid phase serology for the study of human erythrocyte antigen-antibody reactions. Proceedings, Plenary session, 25th Congress, Paris: International Society of Blood Transfusion; 1978.

11. Uthemann H, Poschmann A. Solid-phase antiglobulin test for screening and identification of red cell antibodies. Transfusion. 1990;30(2):114 116.

12. Lapierre Y, Rigal D, Adam J, et al. The gel test: a new way to detect red cell antigen-antibody reactions. Transfusion. 1990;30(2):109-113.

13. Winters JL, Richa EM, Bryant SC, et al. Polyethylene glycol antiglobulin tube versus gel microcolumn: influence on the incidence of delayed hemolytic transfusion reactions and delayed serologic transfusion reactions. Transfusion. 2010;50(7):1444-1452.

14. Brigid SM. The Use of papain and bromelin in blood bank screening procedures: an evaluation and comparison with standard technics. Transfusion. 1961;1(5):321-330.

15. Lalezari P. A Polybrene method for the detection of red cell antibodies. Fed Proc. 1967;26:756.

16. Lalezari P. A New method for detection of red blood cell antibodies. Transfusion. 1968;18(6):372-380.

17. Sherwood GK, Haynes BF, Roose WF. Hemolytic transfusion reactions caused by failure of commercial antiglobulin reagents to detect complement. Transfusion. 1976;16(5):417-420.

18. Snyder EL, Spivack M, Novodoff D, et al. Hemolytic anti-hr" (e) detectable solely by an automated polybrene technique. Transfusion. 1978;18(1):79-83.

19. Maynard BA, Smith DS, Farrar RP, et al. Anti-Jk ${ }^{\mathrm{a}}$, -C, and -E in a single patient, initially demonstrable only by the manual hexadimethrine bromide (Polybrene) test, with incompatibilities confirmed by ${ }^{51} \mathrm{Cr}$ labeled red cell studies. Transfusion. 1978;28(3):302-306.

20. Powers A, Chandrashekar S, Mohammed M, et al. Identification and evaluation of false-negative antibody screens. Transfusion. 2010;50(3):617-621.

21. Liu JC, Wang Y, Liu FP, et al. The manual Polybrene test has limited sensitivities for detecting the Kidd blood group system. Scand J Clin Lab Invest. 2009;69(7):797-800.

22. Letendre PL, Williams MA, Ferguson DJ. Comparison of a commercial hexadimethrine bromide method and low-ionic-strength solution for antibody detection with special reference to anti-K. Transfusion. 1987;27(2):138-141.

23. Lalezari P, Jiang AF. The manual polybrene test: a simple and rapid procedure for detection of red cell antibodies. Transfusion. 1980;20(2):206-211.

24. Shirey RS, Boyd JS, Ness PM. Polyethylene glycol versus low-ionicstrength solution in pretransfusion testing: a blinded comparison study. Transfusion. 1994;34(5):368-370.

25. Reisner RK, Butler GW, Bundy KL et al. Comparison of the polyethylene glycol antiglobulin test and the use of enzymes in antibody detection and identification. Transfusion.1996;36(6):487-489.

26. Weisbach V, Ziener A, Zimmermann R, et al. Comparison of the performance of four microtube column agglutination systems in the detection of red cell alloantibodies. Transfusion. 1999;39(10):10451050 .

27. Finck R, Lui-Deguzman C, Teng SM, et al. Comparison of a gel microcolumn assay with the conventional tube test for red blood cell alloantibody titration. Transfusion. 2013;53(4):811-815. 
28. Pinkerton $\mathrm{PH}, \mathrm{Chan} \mathrm{R}$, Ward J, et al. Sensitivity of column agglutination technology in detecting unexpected red cell antibodies. Transfus Med. 1993;3(4):275-279.

29. Phillips PK, Whitton CM, Lavin F. The use of the antiglobulin 'gel-test' for antibody detection. Transfus Med. 1992;2(2):111-113.

30. Winters JL, Richa EM, Bryant SC, et al. Polyethylene glycol antiglobulin tube versus gel microcolumn: influence on the incidence of delayed hemolytic transfusion reactions and delayed serologic transfusion reactions. Transfusion. 2010;50(7):1444-1452.
31. Noumsi GT, Billingsley KL, Moulds JM. Successful transfusion of antigen positive blood to alloimmunised patients using a monocyte monolayer assay. Transfus Med. 2015;25(2):92-100. 